\title{
Hydrothermal conversion of lignin model compound eugenol
}

\author{
Xavier Besse, Yves Schuurman, Nolven Guilhaume * \\ Université Lyon 1, Institut de recherches sur la catalyse et l'environnement de Lyon IRCELYON, UMR5256 CNRS, 2 avenue Albert Einstein, F-69626 \\ Villeurbanne Cédex, France
}

\begin{abstract}
The hydrothermal conversion of eugenol over a Pt/C catalyst at temperatures between 250 and $300^{\circ} \mathrm{C}$ in a water/ethanol mixture in the absence of gaseous $\mathrm{H}_{2}$ was investigated using various catalysts. Under these conditions, the $\mathrm{C} C$ double bond of the propenyl chain is hydrogenated, but the hydroxyl and methoxy groups of eugenol do not react. The reaction can be described by a two-step process. The first step is the isomerization of the double bond on the alkyl chain of eugenol. The second step is the hydrogenation of this double bond, hydrogen being supplied by ethanol, which is converted into acetaldehyde. The kinetics of the two-step process can be adequately described by a Langmuir-Hinshelwood mechanism with all components in quasi-adsorption equilibrium on a single site $\left(\mathrm{Pt}_{\mathrm{s}}\right)$ and the surface steps as ratedetermining.
\end{abstract}

\section{Introduction}

Lignin is one of the three main components of lignocellulosic biomass, representing $15-25 \%$ of its dry mass, with cellulose (30-50wt.\%) and hemicellulose (20-35 wt.\%). Lignin is a natural polymer made essentially from three phenol-based building blocks, p-coumaryl alcohol, coniferyl alcohol and sinapyl alcohol, linked randomly by $\mathrm{C}-\mathrm{C}$ or $\mathrm{C}-\mathrm{O}-\mathrm{C}$ bonds. It is produced in large amounts as a by-product of the pulp and paper industries, which extract and utilize only the cellulose and hemicellulose fibers from the biomass, and it is essentially burnt as a low-value fuel. However, lignin could potentially represent a major renewable source for aromatic compounds by conversion into useful chemicals and fuels [1].

Hydrothermal liquefaction of biomass is an interesting process in order to transform biomass resources containing large amounts of water, since it does not require a costly drying step of the biomass feedstock. Under sub-critical water conditions $\left(250-350^{\circ} \mathrm{C}, 40-160 \mathrm{bar}\right)$, hydrothermal depolymerization of lignin leads to the formation of its main building molecules (coniferyl, p-coumaryl and sinapyl alcohols), which can further react through hydrolysis, demethoxylation or dealkylation reactions, depending on the reaction conditions, to form

\footnotetext{
* Corresponding author. Tel.: +33 472445 389; fax: +33 472445399.

E-mail address: Nolven.Guilhaume@ircelyon.univ-lyon1.fr (N. Guilhaume).
}

various phenol-derived compounds [2,3]. Lignin depolymerization takes place under rather mild hydrothermal conditions in the presence of mineral acids or bases [4,5], while the addition of polar organic solvents also favors the depolymerization and prevents the re-polymerization of monomers and oligomers [6-8]. Different phenol-based monomers (phenols, anisole, guaiacol, cresol) and various dimers have been studied as lignin model compounds [9]. Most studies focus on reducing the oxygen content through hydrodeoxygenation reactions under high hydrogen pressure, with the objective of producing biofuels [10-14].

The objective of the present study was to investigate the reactivity of eugenol, chosen as lignin model molecule, in the absence of a reducing gas such as $\mathrm{H}_{2}$, but in a water/ethanol mixture, ethanol serving as hydrogen-donor solvent. Ethanol can be produced from renewable sources, and it is also the solvent used in the Organosolv fractionation process to separate lignin from lignocellulosic biomass. Eugenol (or 2-methoxy-4-(2-propenyl)phenol) presents essentially the same chemical groups as coniferyl alcohol, with the exception of the terminal hydroxyl group on the propenyl chain (Fig. 1). The other objectives were to identify which chemical groups of the eugenol molecule might be reactive under such conditions, to study the reaction kinetics and to propose a kinetic model for eugenol reactions.

Several catalysts were synthesized and tested for the conversion of eugenol in a water/ethanol solution, and the best catalyst was selected for kinetic studies. 
<smiles>OC/C=C/c1ccc(O)cc1</smiles>

p-coumaryl alcohol<smiles>COc1cc(/C=C/CO)ccc1O</smiles>

coniferyl alcohol<smiles>C=CCc1ccc(O)c(OC)c1</smiles>

eugenol<smiles>COc1cc(C=CCO)cc(OC)c1O</smiles>

sinapyl alcohol
Fig. 1. The three monomeric building blocks of lignin and model molecule eugenol.

\section{Experimental}

\subsection{Catalyst preparation}

Eugenol (reagent Plus, 99\%), ethanol and $\operatorname{Pd}(\mathrm{II})$ nitrate were purchased from Sigma-Aldrich. $\mathrm{Ru}(\mathrm{III})$ nitrosylnitrate and $\mathrm{Pt}\left(\mathrm{NH}_{3}\right)_{4}(\mathrm{OH})_{2}$ were supplied by Alfa Aesar. The carbon support was calcined at $500{ }^{\circ} \mathrm{C}$ under $\mathrm{N}_{2}$ for $5 \mathrm{~h}$. Zirconia was calcined at $600^{\circ} \mathrm{C}$ in air for $5 \mathrm{~h}$. The metal precursors were deposited on the supports by wet impregnation in a water solution during $30 \mathrm{~min}$ in order to obtain 1 wt.\% of Pd and Ru on the support and 2 wt.\% of Pt. These loadings correspond to a similar molar loading, close to $0.01 \mathrm{~mol}$ \% for the three metals. The mixture was then dried using a rotatory evaporator and calcined at $500{ }^{\circ} \mathrm{C}$ for carbon supported catalysts and $600{ }^{\circ} \mathrm{C}$ in air for zirconia supported catalysts. A reduction was then applied at $300^{\circ} \mathrm{C}$ for $2 \mathrm{~h}$ under a hydrogen flow.

\subsection{Reactor and kinetic studies}

The reactions were performed in a $250 \mathrm{~mL}$ Hastelloy autoclave (Parr) equipped with high-pressure valves for liquid or gaseous introduction and sampling, under autogenous pressure. In a typical experiment, the reactor was loaded with water and the desired amount of catalyst, then purged under flowing nitrogen bubbling in the water for $10 \mathrm{~min}$ in order to remove gaseous air and dissolved oxygen. The heating system was then started and stabilized at the desired temperature in about $30 \mathrm{~min}$. The mixture of eugenol in ethanol was injected in the autoclave using a high-pressure preparative HPLC pump. Injection time was fixed at $2 \mathrm{~min}$. The total liquid volume loaded in the autoclave was always $150 \mathrm{~mL}$. The stirring rate was set at $300 \mathrm{rpm}$. In tests performed at $600 \mathrm{rpm}$ the eugenol disappearance rate was not modified, showing therefore that the reaction was not limited by external mass transfer at $300 \mathrm{rpm}$. The $\mathrm{Pt} / \mathrm{C}$ catalyst used in kinetic studies had a specific surface area of $970 \mathrm{~m}^{2} \mathrm{~g}^{-1}$, with a mean particle size of $16 \mu \mathrm{m}$. The Thiele modulus value, calculated assuming for eugenol a similar effective diffusion coefficient $\left(0.917 \times 10^{-5} \mathrm{~cm}^{2} / \mathrm{s}\right)$ as aqueous phenol solutions in the pores of activated carbon [15] was 0.023 , indicating that internal diffusion limitations are negligible. The Pt dispersion

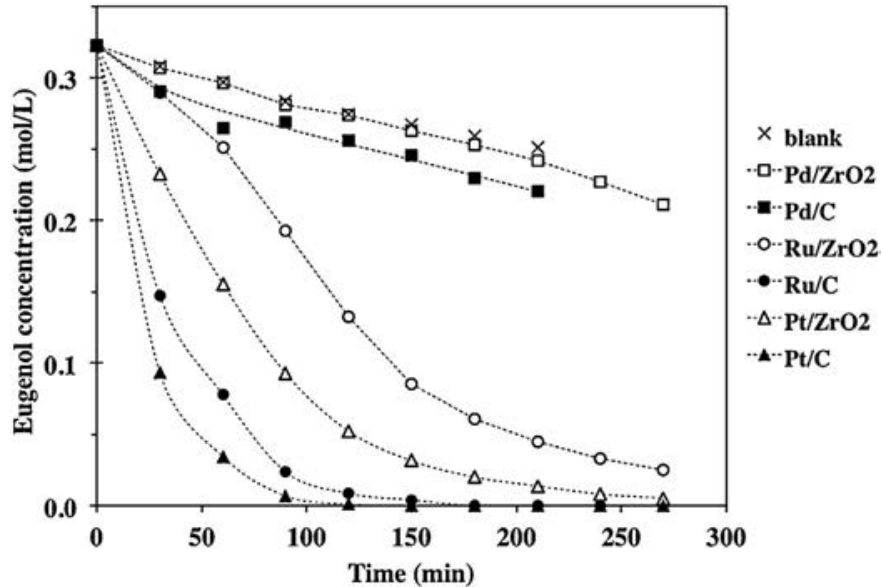

Fig. 2. Effect of catalysts on eugenol reaction in a water/ethanol mixture under autogenous pressure. Conditions: 5 vol.\% eugenol, 45 vol.\% ethanol, 50 vol.\% water, $300^{\circ} \mathrm{C}, P=120$ bar, 1 wt.\% catalyst (relative to eugenol).

measured by $\mathrm{H}_{2}$ chemisorption was $16.3 \%$. Pt leaching was assessed by hydrothermal ageing of $\mathrm{Pt} / \mathrm{C}$ catalyst in water at $320^{\circ} \mathrm{C}$ for $3 \mathrm{~h}$. The Pt content analyzed in water after ageing was $0.1 \mathrm{ppm}$, which represents less than $0.006 \%$ of total Pt introduced.

Kinetic studies were carried out between 250 and $300^{\circ} \mathrm{C}$, with a eugenol concentration between 0.25 vol.\% and 5 vol.\% and using a catalyst concentration varying from $0.66 \mathrm{wt} . \%$ to $1.33 \mathrm{wt} . \%$. Liquid samples $(1 \mathrm{~mL})$ were periodically collected using a liquid sampling valve and were analyzed by GC/MS.

\subsection{GC/MS analysis}

Eugenol and the reaction products were analyzed by GC/MS (Shimadzu QP 2010) on a ZB-WAX plus column $(60 \mathrm{~m} \times 0.25 \mathrm{~mm} \times 0.25 \mu \mathrm{m})$. The GC oven temperature was programmed from $95^{\circ} \mathrm{C}$ to $250^{\circ} \mathrm{C}(10 \mathrm{~min})$ with a heating rate of $15 \mathrm{~K} / \mathrm{min}$. The split ratio was 300:1. The interface temperature between the chromatograph and the mass spectrometer was $260^{\circ} \mathrm{C}$ and the ion source was maintained at $250^{\circ} \mathrm{C}$.

\subsection{Modeling}

The modeling is based on a homogeneous batch reactor. All components were expressed as concentrations to calculate the rate. The concentration profiles of all components as a function of time were obtained by numerical integration. Non-linear least-square regression analysis has been performed by a Levenberg-Marquardt minimization algorithm. After the regression procedure a statistical analysis was performed.

\section{Results and discussion}

\subsection{Catalyst performances and eugenol reaction pathway}

The catalysts were tested at $300^{\circ} \mathrm{C}$ in the autoclave loaded with $75 \mathrm{~mL}$ of water and $1 \mathrm{wt} . \%$ of catalyst relatively to eugenol. A mixture constituted of $7.5 \mathrm{~mL}$ of eugenol in $67.5 \mathrm{~mL}$ ethanol was injected in the hot autoclave in $2 \mathrm{~min}$. The autogenous pressure of the mixture was 120 bar at $300^{\circ} \mathrm{C}$. The concentration of eugenol vs. time using different catalysts is shown in Fig. 2.

Palladium catalysts exhibit virtually no activity towards eugenol, whereas ruthenium and platinum catalysts strongly improve the reaction rate. At similar metal loadings, carbon supported catalysts are more active than zirconia supported catalysts. $\mathrm{Pt} / \mathrm{C}$ is the best catalyst, after $30 \mathrm{~min}$ of reaction $80 \%$ of eugenol 


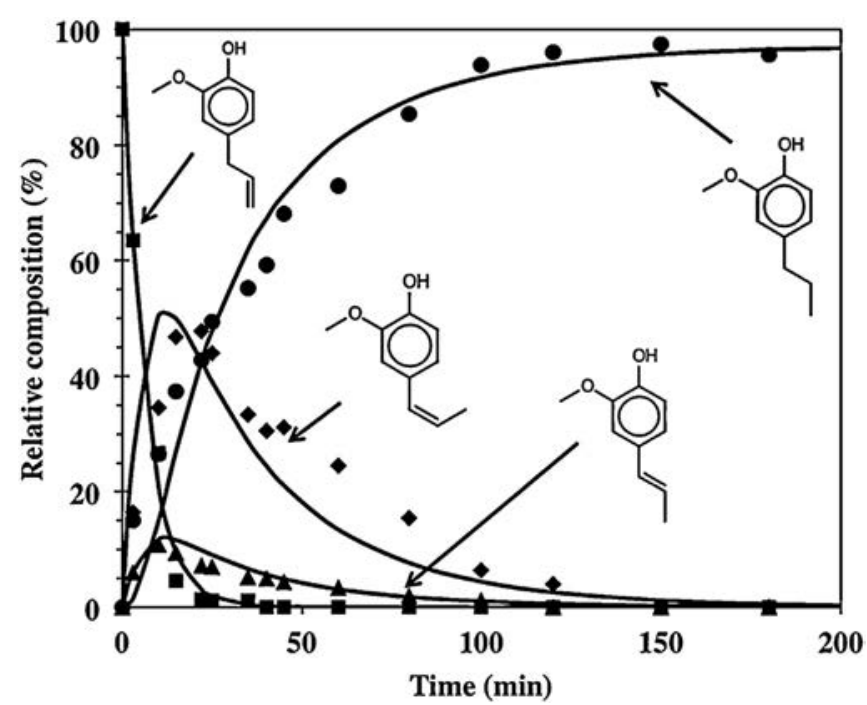

Fig. 3. Products composition profile as a function of time with $\mathrm{Pt} / \mathrm{C}$ catalyst. Symbols represent experimental data, thick lines are the kinetic model fit to the data. Conditions: 1.25 vol.\% eugenol, 45 vol.\% ethanol, 53.75 vol.\% water, $250^{\circ} \mathrm{C}, P=60$ bar, $75 \mathrm{mg} \mathrm{Pt} / \mathrm{C}$.

has been transformed and the conversion is total after $100 \mathrm{~min}$. This catalyst was therefore selected to perform a kinetic study of eugenol reactions.

The products composition profile obtained during eugenol reactions in a water/ethanol mixture is displayed in Fig. 3. Three products were identified by GC-MS: two position isomers ( $\mathrm{Z}$ and $\mathrm{E}$ ) in which the double bond on the propenyl chain was displaced from position 2-3 to position 1-2 (2-methoxy-4-(1-propenyl)phenol or iso-eugenol) and one product in which the double bond has been hydrogenated (2-methoxy-4-propylphenol, referred to as "P" in the kinetic model). Acetaldehyde formation was identified in some specific analyses where the samples were analyzed immediately after withdrawal from the autoclave and the GC oven temperature programme was started at $45^{\circ} \mathrm{C}$, which confirms that hydrogen is supplied by ethanol. We were not able, however, to quantify acetaldehyde formation because it is highly volatile (boiling point $20.8^{\circ} \mathrm{C}$ ) and tends to evaporate from the solutions, leading to irreproducible results. In the blank experiment, the $\mathrm{Z}$ isomer of iso-eugenol was the most abundant product formed. Experiments carried out under similar conditions with only the carbon support (not shown) revealed a low conversion of eugenol (10\% after 150 min of reaction), with $63 \%$ selectivity in iso-eugenol $\mathrm{Z}$ and $\mathrm{E}$ isomers and $37 \%$ selectivity in 2-methoxy-4-propylphenol.

Eugenol hydrogenation by $\mathrm{Pt} / \mathrm{C}$ catalyst in the presence of ethanol is limited since only the $\mathrm{C}=\mathrm{C}$ double bond is hydrogenated, whereas the hydroxyl and methoxy groups and the aromatic ring are unreactive under such condition. Indeed, the $\mathrm{Ar}-\mathrm{O}$ bonds dissociation energies are very high ( 422 and $468 \mathrm{~kJ} / \mathrm{mol}$ for Ar-OR and $\mathrm{Ar}-\mathrm{OH}$, respectively) and aromatic ethers and alcohols are more difficult to deoxygenate than the corresponding aliphatic compounds [9]. It should be mentioned that 2-methoxy-4-propylphenol was the second most abundant product $(\approx 12 \%)$ formed in hydrogenation experiments of lignin $\left(2 \mathrm{MPa}_{2}\right)$ in a water/ethanol mixture in the presence of a tungsten phosphide catalyst [16]. In our experiments, no gaseous hydrogen is present but Pt appears to also catalyze the oxidation of ethanol into acetaldehyde to form hydrogen in-situ. Several other studies performed on lignin model compounds and on lignin reported that $\mathrm{C}-\mathrm{O}$ bonds can be cleaved and the aromatic ring hydrogenated under hydrogen pressure in the presence of Mo-based HDO catalysts (CoMo [17], NiMo sulphides [18]) or Raney Ni $[19,20]$. It should be noticed, however, that

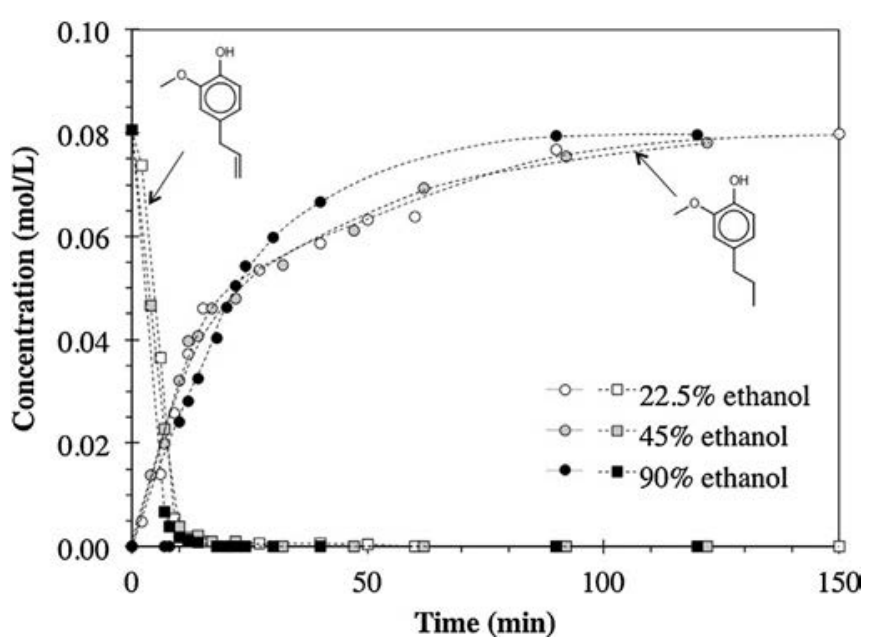

Fig. 4. Effect of ethanol concentration on the product composition profiles ( $\mathrm{Z}$ and E iso-eugenol isomers are not shown). Conditions: 1.25 vol.\% eugenol, $22.5,45$ or $90 \mathrm{vol} . \%$ ethanol (corresponding pressure $=50,60$ or 70 bar, respectively), balance water, $250^{\circ} \mathrm{C}, 75 \mathrm{mg} \mathrm{Pt} / \mathrm{C}$.

in some studies the reactant/catalyst ratio used is very low (i.e. in [20], 1 or $2 \mathrm{mmol}$ of aromatic ether or phenol (around $0.2 \mathrm{~g}$ ) is reacted in the presence of $1 \mathrm{~g}$ Raney $\mathrm{Ni}$, which raises the question of the deoxygenation reaction being catalyzed by $\mathrm{Ni}$ or resulting from the stoichiometric oxidation of $\mathrm{Ni}$ by the substrate. Indeed, metallic $\mathrm{Zn}$, Fe or Mn powders have been shown to behave as efficient reductants for the deoxydehydration of polyols such as 1,2-decanediol or 1-phenyl-1,2-ethanediol, leading to quantitative yields of deoxygenated compounds with simultaneous formation of the metal oxides [21].

The effect of ethanol concentration on the reaction profile is displayed in Fig. 4. Changing the ethanol concentration from $22.5 \%$ to $90 \%$ does not modify strongly the eugenol reaction rates, although its disappearance is slightly faster at high ethanol concentration, or the formation of 2-methoxy-4-propylphenol (for the sake of clarity, the concentration profiles of $Z$ and $E$ iso-eugenol are not shown, since they are roughly similar in the three experiments). The autogenous pressure developed at $250{ }^{\circ} \mathrm{C}$ in the autoclave is different depending on ethanol concentration ( 50,60 or 70 bar at $22.5,45$ or 90 vol.\% ethanol, respectively), but this parameter does not strongly impact the eugenol reaction, which suggests that there is no implication of gas-phase products in the reaction, and that ethanol is always in large excess.

Substituting n-butanol for ethanol as H-donor solvent leads to slow down the formation of the hydrogenated product (2methoxy-4-propylphenol) but does not strongly modify the reaction pathway (Fig. 5).

\subsection{Kinetic study}

The influence of eugenol concentration on the initial rates of eugenol disappearance and products formation is shown in Fig. 6. The reaction rates increase linearly with the initial eugenol concentration up to $\approx 0.1 \mathrm{~mol} / \mathrm{L}$, but tend to decrease at higher eugenol concentrations. This suggests a competitive adsorption of the two reactants, eugenol and ethanol, on the same catalytic sites. Increasing the eugenol concentration initially leads to a more optimal surface concentration of the two adsorbed species, resulting in an increase of the reaction rate, until the eugenol surface concentration is too high and inhibits ethanol adsorption, consequently the reaction rate decreases at high eugenol concentrations. For this reason, the kinetic study was performed with an eugenol concentration of $1.25 \mathrm{vol} . \%(0.079 \mathrm{~mol} / \mathrm{L})$. 


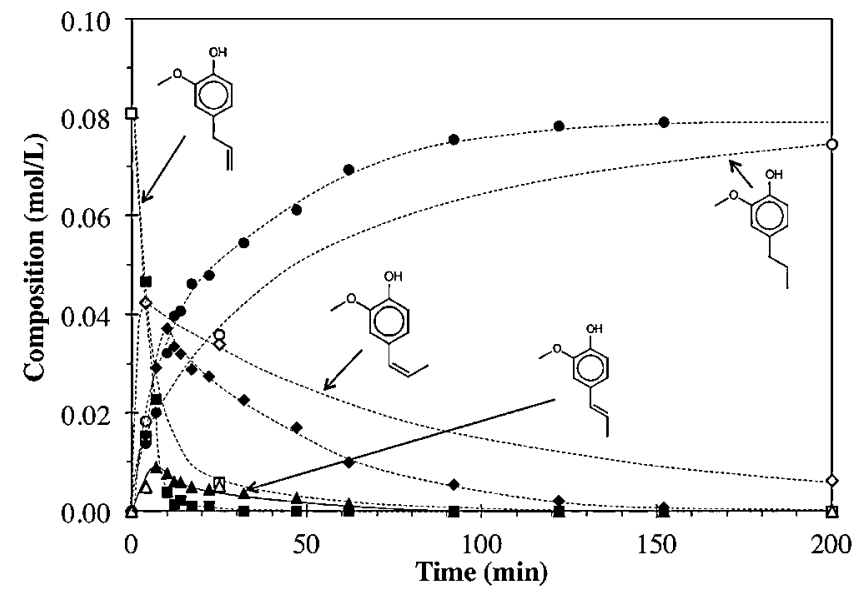

Fig. 5. Effect of alcohol used as H-donor solvent on the product composition profiles. Full symbols: ethanol; open symbols: n-butanol. Conditions: $1.25 \mathrm{vol} . \%$ eugenol, 45 vol.\% alcohol, 53.75 vol.\% water, $75 \mathrm{mg} \mathrm{Pt} / \mathrm{C}, 250^{\circ} \mathrm{C}, P=60$ bar with ethanol, $P=35$ bar with n-butanol.

In order to ensure that the reaction is operated under kinetic control, the effect of the catalyst mass on the conversion of eugenol was investigated. Fig. 7 shows that the initial rates of eugenol disappearance and products formation, expressed per gram of catalyst, are constant at the three catalyst loadings studied. Consequently, the reaction can be considered to operate in the absence of external mass transfer limitations.

The effect of reaction temperature on eugenol reaction rates is depicted in Fig. 8. As expected, eugenol is transformed more rapidly when the temperature increases, but the final product remains 2-methoxy-4-propylphenol. The apparent activation energy for the disappearance of eugenol calculated from Arrhenius plots is $48 \mathrm{~kJ} / \mathrm{mol}$, which is consistent with the apparent activation energy for the eugenol $\rightarrow$ iso-eugenol reaction catalyzed by $\mathrm{RhCl}_{3}$, a homogeneous catalyst, in ethanol $(42.6 \mathrm{~kJ} / \mathrm{mol})$ [22]. The apparent activation energy for the formation of the final product 2-methoxy4-propylphenol is $56 \mathrm{~kJ} / \mathrm{mol}$.

Eugenol has been shown to undergo HDO reactions (cleavage of methoxy and hydroxyl C-O bonds) in aqueous phase at $240^{\circ} \mathrm{C}$ under $5 \mathrm{MPa} \mathrm{H}_{2}$ pressure in the presence of Pd/C catalyst combined

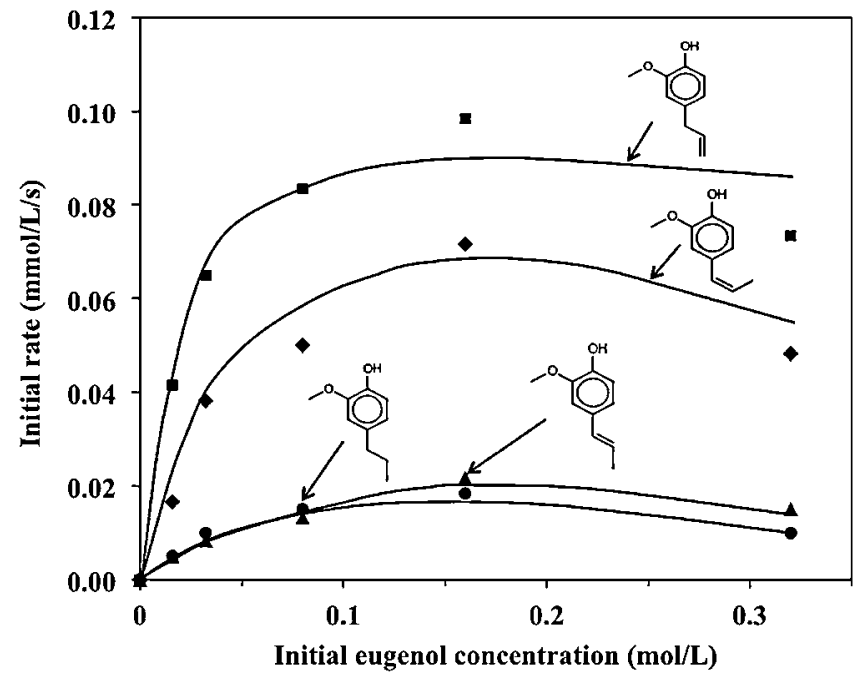

Fig. 6. Effect of eugenol concentration on initial rates of reaction. Symbols represent experimental data, thick lines are the kinetic model fit to the data. Conditions: $0.25-5 \mathrm{vol} \%$ eugenol $(0.016-0.323 \mathrm{~mol} / \mathrm{L}), 45 \mathrm{vol} . \%$ ethanol, balance water, $75 \mathrm{mg}$ $\mathrm{Pt} / \mathrm{C}, 250^{\circ} \mathrm{C}, \mathrm{P}=60$ bar.

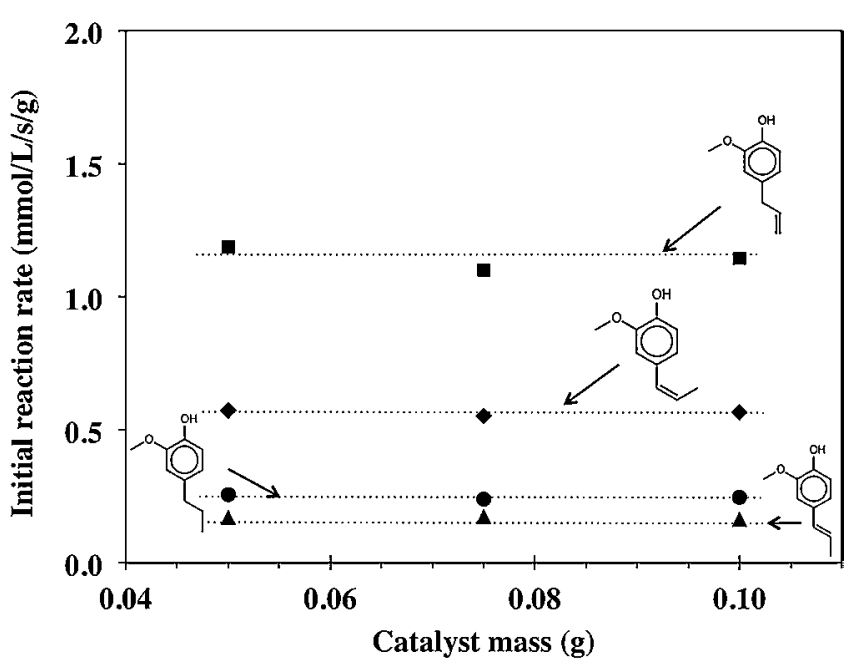

Fig. 7. Effect of catalyst mass on initial rates of eugenol disappearance and products formation. Conditions: 1.25 vol.\% eugenol, 45 vol. \% ethanol, 53.75 vol.\% water, $250^{\circ} \mathrm{C}, P=60 \mathrm{bar}$

with HZSM-5 [11]. In the absence of zeolite catalyst, however, the propenyl group and the aromating ring of eugenol were essentially hydrogenated, but the methoxy and hydroxyl groups were not removed. Phenol was also shown to undergo significant gas phase hydrodeoxygenation at $250{ }^{\circ} \mathrm{C}$ under 15 bar $\mathrm{H}_{2}$ in the presence of a $\mathrm{Pd}(1 \%) / \mathrm{HY}-\mathrm{Al}_{2} \mathrm{O}_{3}$ catalyst $\left(\mathrm{H}_{2}\right.$ :phenol ratio of $\left.100: 1\right)$ [23]. We investigated therefore the effect of $\mathrm{HY}$ zeolite as co-catalyst under our reaction conditions, i.e. with ethanol as $\mathrm{H}$-donor solvent but in the absence of gaseous hydrogen.

Fig. 9 compares the reaction profiles obtained with Pt/C, HY and Pt/C + HY catalysts.

HY zeolite does not display any significant activity (similar to blank experiments). Although solid acids such as zeolites, silica-aluminas and sulphated zirconia are known to catalyze isomerization of olefins, HY itself is not active for eugenol isomerization under the present reaction conditions. When $\mathrm{HY}$ is added to $\mathrm{Pt} / \mathrm{C}$ catalyst, the initial rate of eugenol disappearance is similar to the rate with $\mathrm{Pt} / \mathrm{C}$ but its hydrogenation product forms less rapidly (Fig. 9A), which leads intermediately to a more important accumulation of isomerization products (Fig. 9B). HY appears to inhibit the hydrogenation reaction, perhaps by adsorbing the isomerization products more strongly than $\mathrm{Pt} / \mathrm{C}$.

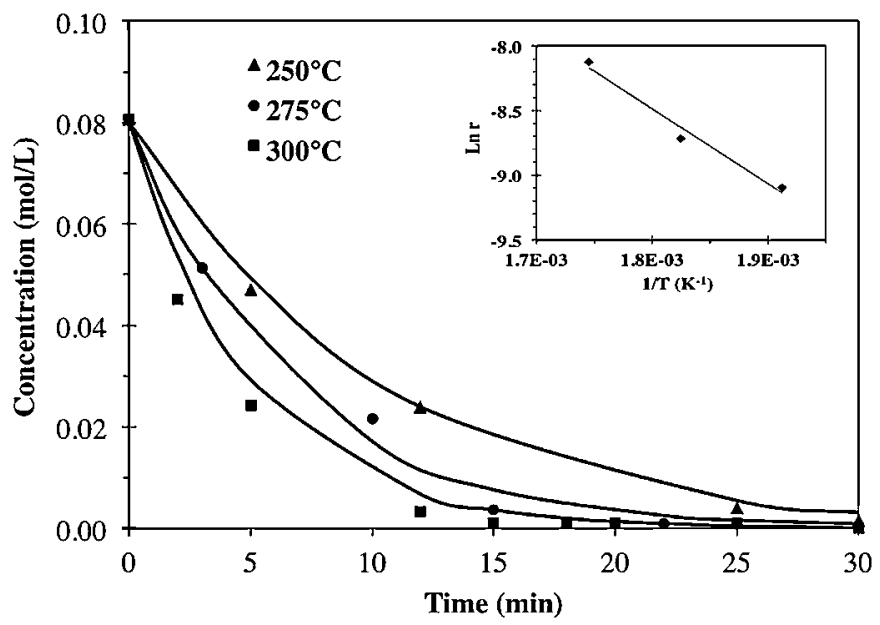

Fig. 8. Eugenol concentration profiles at 250,275 and $300^{\circ} \mathrm{C}(P=60,80$ and 120 bar, respectively). The lines show the kinetic model results. Conditions: 1.25 vol.\% eugenol, 45 vol.\% ethanol, 53.75 vol.\% water. 

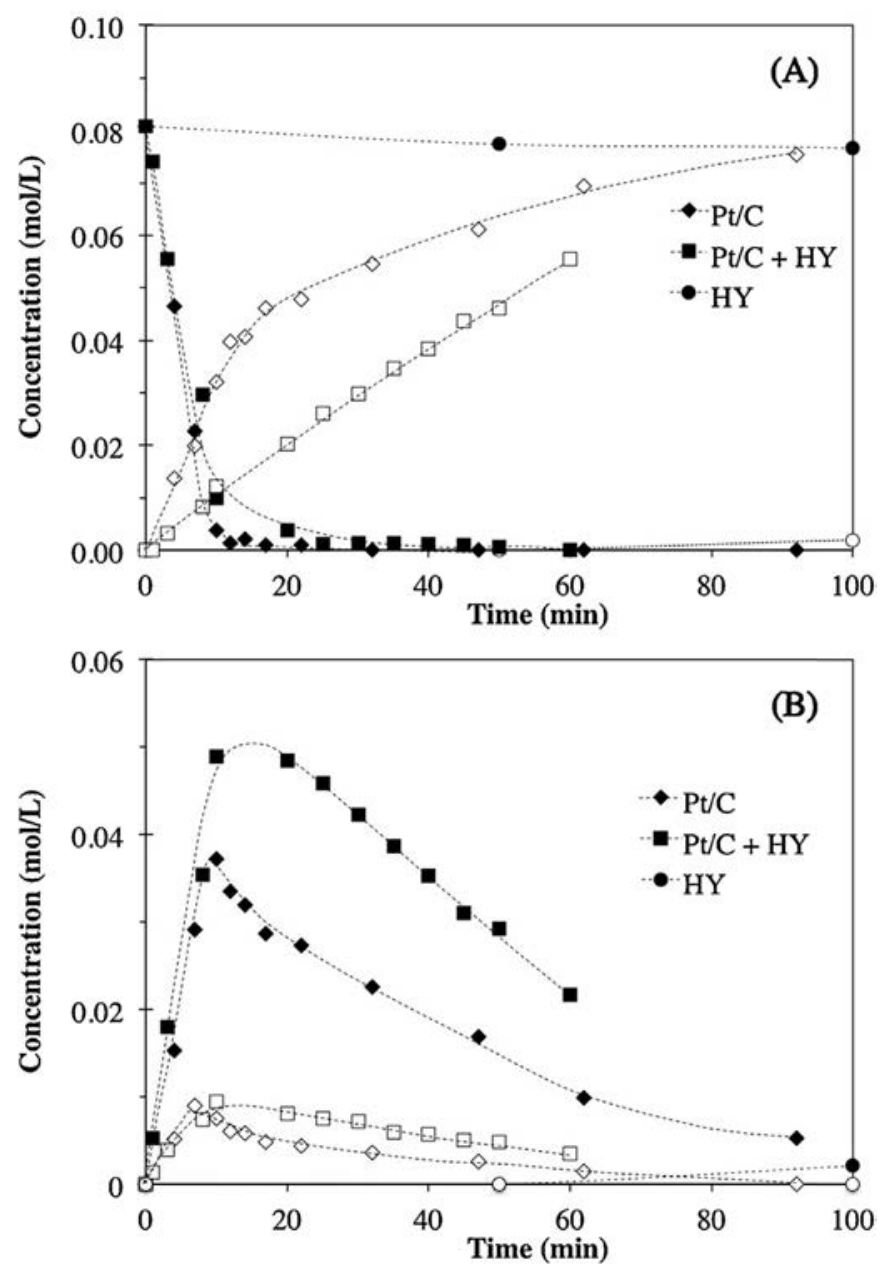

Fig. 9. Comparison of product composition profiles in the presence of Pt/C (75 mg), Pt/C (75 mg) + HY (375 mg) or HY (375 mg) catalysts. (A): eugenol (full symbols) and its hydrogenation product 2-methoxy-4-propylphenol (open symbols). (B) isomerization products Z-iso-eugenol (full symbols) and E-iso-eugenol (open symbols) Conditions: 1.25 vol.\% eugenol, 45 vol.\% ethanol, 53.75 vol. $\%$ water, $250^{\circ} \mathrm{C}, P=60$ bar.

\subsection{Modeling and reaction mechanism}

Fig. 10 gathers the yields of $\mathrm{Z}, \mathrm{E}$ isomers and hydrogenation product $\mathrm{P}$ as a function of eugenol conversion for all experiments.

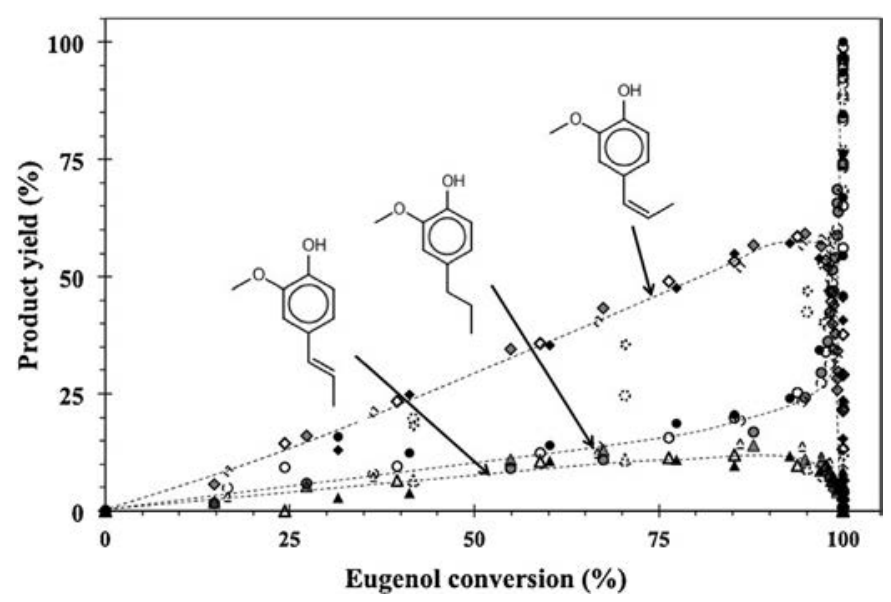

Fig. 10. Product yields as a function of eugenol conversion for all experiments performed.
Table 1

Estimated and fixed parameters for the reaction steps (1)-(6). The estimated parameters are given with their respective $95 \%$ confidence intervals.

\begin{tabular}{llll}
\hline Rate constant $(\mathrm{mol} / \mathrm{kg} / \mathrm{s})$ & \multicolumn{3}{c}{ Activation energy $(\mathrm{kJ} / \mathrm{mol})$} \\
\hline$k_{2}$ & $1.9 \pm 0.3$ & $E_{2}$ & $83 \pm 14$ \\
$k_{6}$ & $4.0 \pm 0.5$ & $E_{2}$ & $96 \pm 13$ \\
& & & \\
Equilibrium constant $\left(\mathrm{kPa}^{-1}\right)$ & & Adsorption enthalpy $(\mathrm{kJ} / \mathrm{mol})$ \\
\hline$K_{\text {EUG }}[24]$ & 62.2 & $\Delta H_{\text {EUG }}$ & 70 \\
$K_{\mathrm{Z}}[24]$ & 62.2 & $\Delta H_{Z}$ & 70 \\
$K_{4}$ & $15.5 \pm 1$ & $\Delta H_{4}$ & $76 \pm 5$ \\
$K_{\mathrm{P}}[24]$ & 62.2 & $\Delta H_{\mathrm{P}}$ & 70 \\
$K_{\mathrm{EtOH}}[25]$ & 0.88 & $\Delta H_{\mathrm{EtOH}}$ & 29 \\
\hline
\end{tabular}

A linear increase in the yields of $\mathrm{Z}, \mathrm{E}$ and $\mathrm{P}$ is observed from 0 to $85 \%$ conversion. At conversion levels higher than $90 \%$ a sharp drop in the $Z$ and $E$ yields is found together with a steep increase in the yield of $P$. The ratio of $Z / E$ is constant and amounts to approximately 4.7. This constant ratio indicates that the transformation of $\mathrm{Z}$ into $\mathrm{E}$ and $\mathrm{E}$ into $\mathrm{Z}$ is rapid and attains thermodynamic equilibrium. The reaction network can be described by a two-step process, which consists in the isomerization of eugenol into $\mathrm{Z}$ and $\mathrm{E}$ followed by the conversion of $\mathrm{Z}$ and $\mathrm{E}$ into $\mathrm{P}$. The latter reaction needs a hydrogen donor, which is thought to be ethanol as the formation of acetaldehyde has been detected. The following steps were taken into account:

$\mathrm{EUG}+* \Leftrightarrow \mathrm{EUG} *$

$\mathrm{EUG} * \Rightarrow \mathrm{EZ} *$

$\mathrm{EZ} * \Leftrightarrow \mathrm{Z}$

$\mathrm{EZ} * \Leftrightarrow \mathrm{E}$

$\mathrm{EtOH}+2 * \Leftrightarrow \mathrm{EtO} *+\mathrm{H} *$

$\mathrm{EZ} *+2 \mathrm{H} * \Rightarrow \mathrm{P} *$

$\mathrm{P} * \Leftrightarrow \mathrm{P}$

The further conversion of the ethoxy species EtO* into acetaldehyde $\left(\mathrm{EtO}^{*}+{ }^{*} \Rightarrow\right.$ acetaldehyde $+\mathrm{H}^{*}+{ }^{*}$ ) has not been taken into account, as acetaldehyde could only be detected qualitatively and ethanol was in large excess. In the above scheme, ${ }^{*}$ stands for a surface platinum atom which acts as active site. The amount of surface platinum atoms was measured by volumetric hydrogen desorption and amounted to $1.1 \times 10^{-2} \mathrm{~mol} / \mathrm{kg}_{\text {cat }}$. In the above model Langmuir adsorption was assumed for all components.

To get insight into the intrinsic rates, the sorption equilibria on Pt were fixed at values from literature data [24,25], e.g. steps (1), (3), (5), (7), see Table 1 . The equilibrium constant for step (4) has been estimated as it is lumped with the constant for the isomerization equilibrium. The rate constants for the two remaining surface reaction steps, (2) and (6) have been estimated by regression analysis of all experiments simultaneously. The estimated parameters with their 95\% confidence intervals are given in Table 1 . All parameters were estimated with good accuracy and no correlation was found between the parameters. A F-value of more than 3000 was found, indicating an adequate fit. A comparison between the model fit and the experimental concentrations are given in Figs. 3 and 8 by the full lines. A comparison between the experimental initial rates and those calculated by the model is given in Fig. 6 .

Assuming a similar adsorption enthalpy for $\mathrm{E}$ as for $\mathrm{Z}$, a reaction enthalpy of $11 \mathrm{~kJ} / \mathrm{mol}$ can be calculated for the isomerization between $\mathrm{Z}$ and $\mathrm{E}$. The measured apparent activation energy of $48 \mathrm{~kJ} / \mathrm{mol}$ for the conversion of eugenol consist thus of the enthalpy of eugenol adsorption, $-70 \mathrm{~kJ} / \mathrm{mol}$ and an intrinsic activation energy of $96 \mathrm{~kJ} / \mathrm{mol}$ for surface step (2). 


\section{Conclusion}

The hydrothermal conversion of eugenol at temperatures between 250 and $300^{\circ} \mathrm{C}$ in a water/ethanol mixture was investigated using various catalysts, of which $\mathrm{Pt} / \mathrm{C}$ was the most active. Under these conditions, the $\mathrm{C}=\mathrm{C}$ double bond of the propenyl chain is hydrogenated, but the hydroxyl and methoxy groups are unreactive. The reaction can be described by a two-step process. The first step is the isomerization of the double bond on the alkyl chain of eugenol. The second step is the hydrogenation of this double bond. The hydrogen donor is ethanol, which is converted into acetaldehyde. The kinetics of the two-step process can be adequately described by a Langmuir-Hinshelwood mechanism with all components in quasi-adsorption equilibrium on a single site $\left(\mathrm{Pt}_{\mathrm{s}}\right)$ and the surface steps as rate-determining.

\section{Acknowledgement}

This work has been carried out with the financial support of ANR through the LIQHYD project (ANR-12-BIME-003).

\section{References}

[1] J. Zakzeski, P.C.A. Bruijnincx, A.L. Jongerius, B.M. Weckhuysen, Chem. Rev. 110 (2010) 3552-3599.

[2] S.S. Toor, L. Rosendahl, A. Rudolf, Energy 36 (2011) 2328-2342.

[3] P. Azadi, O.R. Inderwildi, R. Farnood, D.A. King, Renew. Sustain. Energy Rev. 21 (2013) 506-523.

[4] T.D.H. Nguyen, M. Maschietti, T. Belkheiri, L.-E. Amand, H. Theliander, L. Vamling, L. Olausson, S.-I. Andersson, J. Supercrit. Fluids 86 (2014) 67-75.
[5] A.A. Peterson, F. Vogel, R.P. Lachance, M. Fröling, M.J. Antal Jr., J.W. Tester, Energy Environ. Sci. 1 (2008) 32-65.

[6] G. van Rossum, W. Zhao, M. Castellvi Barnes, J.-P. Lange, S.R.A. Kersten, ChemSusChem 7 (2014) 253-259.

[7] S. Hu, X. Luo, Y. Li, ChemSusChem 7 (2014) 66-72.

[8] S. Feng, Z. Yuan, M. Leitch, C.C. Xu, Fuel 116 (2014) 214-220

[9] H. Wang, J. Male, Y. Wang, ACS Catal. 3 (2013) 1047-1070.

[10] B. Güvenatam, O. Kursun, E.H.J. Heeres, E.A. Pidko, E.J.M. Hensen, Catal. Today 233 (2014) 83-91.

[11] C. Zhang, J. Xing, L. Song, H. Xin, S. Lin, L. Xing, X. Li, Catal. Today 234 (2014) $145-152$.

[12] H. Ohta, B. Feng, H. Kobayashi, K. Hara, A. Fukuoka, Catal. Today 234 (2014) 139-144.

[13] T.M. Huynh, U. Armbruster, M.-M. Pohl, M. Schneider, J. Radnik, D.L. Hoang, B.M.Q. Phan, D.A. Nguyen, A. Martin, ChemCatChem 6 (2014) 1940-1951.

[14] S. Jin, Z. Xiao, C. Li, X. Chen, L. Wang, J. Xing, W. Li, C. Liang, Catal. Today 234 (2014) 125-132.

[15] H. Moon, W.K. Lee, J. Colloid Interface Sci. 96 (1983) 162-171.

[16] X. Ma, Y. Tian, W. Hao, R. Ma, Y. Li, Appl. Catal. A 481 (2014) 64-70.

[17] A.L. Jongerius, P.C.A. Bruijnincx, B.M. Weckhuysen, Green Chem. 15 (2013) 3049-3056.

[18] B. Joffres, C. Lorentz, M. Vidalie, D. Laurenti, A.-A. Quoineaud, N. Charon, A. Daudin, A. Quignard, C. Geantet, Appl. Catal. B 145 (2014) $167-176$.

[19] X. Wang, R. Rinaldi, ChemSusChem 5 (2012) 1455-1466.

[20] X. Wang, R. Rinaldi, Angew. Chem. Int. Ed. 52 (2013) 11499-11503.

[21] J.M.II. McClain, K.M. Nicholas, ACS Catal. 4 (2014) 2109-2112.

[22] L. Červený, A. Krejčiková, A. Marhoul, V. Rǔžička, React. Kinet. Catal. Lett. 33 (1987) $471-476$.

[23] S. Echeandia, B. Pawelec, V.L. Barrio, P.L. Arias, J.F. Cambra, C.V. Loricera, J.L.G. Fierro, Fuel 117 (2014) 1061-1073.

[24] M. Saeys, M.-F. Reyniers, G.B. Marin, M. Neurock, J. Phys. Chem. B 106 (2002) 7489-7498.

[25] R. Alcala, J.W. Shabaker, G.W. Huber, M.A. Sanchez-Castillo, J.A. Dumesic, J. Phys, Chem. B 109 (2005) 2074-2085. 